\title{
Nebulized versus Standard Local Application of Lidocaine during Flexible Bronchoscopy: A Randomized Controlled Trial
}

\author{
Michael Dreher ${ }^{\mathrm{a}}$ Christian Gabriel Cornelissen ${ }^{\mathrm{a}}$ Manuel Armin Reddemann ${ }^{\mathrm{b}}$ \\ Annegret Müller $^{\mathrm{a}}$ Christian Hübel $^{\mathrm{a}}$ Tobias Müller $^{\mathrm{a}}$ \\ ${ }^{a}$ Division of Pneumology, University Hospital RWTH Aachen, and ${ }^{\mathrm{b}}$ Institute of Heat and Mass Transfer, \\ RWTH Aachen University, Aachen, Germany
}

\section{Key Words}

Flexible bronchoscopy $\cdot$ Sedation $\cdot$ Lidocaine $\cdot$ Nebulizer

\begin{abstract}
Background: Endobronchial administration of local anesthetics such as lidocaine is often used for cough suppression during bronchoscopy. To achieve a better distribution of lidocaine in the tracheobronchial tree, spray catheters have been developed, allowing nebulization of the local anesthetic solution. However, there are little data on the efficacy and safety of this approach, or on the consumption of sedative drugs and lidocaine during nebulized administration. Objectives: To investigate the tolerability of nebulized lidocaine compared to conventional lidocaine administration via syringe through the working channel of the bronchoscope in patients undergoing bronchoscopy. Consumption of sedative drugs and lidocaine was also compared between the two lidocaine administration approaches. Methods: Patients requiring bronchoscopy with endobronchial or transbronchial biopsy were randomly assigned to receive topical lidocaine either via syringe or via nebulizer. Endpoints were consumption of lidocaine and sedative drugs, as well as patient tolerance and safety. Results: Thirty patients were in-
\end{abstract}

\section{KARGER}

E-Mail karger@karger.com

www.karger.com/res cluded, 15 in each group. Patients in the nebulizer group required lower doses of endobronchial lidocaine (184.7 \pm 67.98 vs. $250.7 \pm 21.65 \mathrm{mg}, \mathrm{p}=0.0045$ ) and intravenous fentanyl $(0.033 \pm 0.041$ vs. $0.067 \pm 0.045 \mathrm{mg}, \mathrm{p}=0.0236)$ than those in the syringe group; midazolam or propofol dosages did not differ between the two groups. In addition, there were no between-group differences in patient tolerance or safety (all $p>0.05$ ). Conclusion: Endobronchial administration of lidocaine during bronchoscopy via nebulizer was found to be well tolerated and safe and was associated with reduced lidocaine and fentanyl dosages compared to administration via syringe.

(c) 2016 S. Karger AG, Basel

\section{Introduction}

Flexible bronchoscopy is a well-established procedure for the assessment, diagnosis, and management of patients with a variety of respiratory diseases. In order to facilitate the procedure and to reduce coughing, thereby increasing patient tolerance and comfort, patients are usually sedated during bronchoscopy $[1,2]$. Currently, there is no clear recommendation favoring one sedation 
regimen over any other. Nevertheless, a combination of the short-acting benzodiazepine midazolam with propofol (or with different opiates) is used frequently [1-3].

To reduce the requirement for sedative drugs, local anesthetics such as lidocaine are usually administered topically to the bronchial system using a syringe through the working channel of the bronchoscope [4]. However, it might be difficult to obtain an even distribution of lidocaine in the bronchial system using this method, resulting in incomplete anesthesia of the airway walls. Therefore, spray catheters such as the Enk Fiberoptic Atomizer Set ${ }^{\circledR}$ have been developed, which allow nebulization of local anesthetics during the procedure [5]. The device mentioned was initially designed for use during awake fiberoptic intubation using oxygen flow for the nebulization of local anesthetics [6]. Compared to the conventional method of lidocaine administration via syringe, nebulization is likely to achieve a better distribution of lidocaine in the tracheobronchial tree. However, there is currently little evidence to show whether this is associated with better patient tolerance or with reduced need for local anesthetics or sedative drugs. This is particularly relevant when a longer procedural duration is expected, such as when a transbronchial or endobronchial biopsy is indicated.

Therefore, the aim of this study was to investigate whether lidocaine application via the nebulizer system is superior to conventional lidocaine application via syringe with respect to the consumption of sedative drugs or lidocaine, as well as patient comfort and safety.

\section{Material and Methods}

The work was conducted at the University Hospital RWTH Aachen, Aachen, Germany. The study protocol was approved by the Institutional Review Board for Human Studies at RWTH Aachen University, Aachen, Germany, and was performed in accordance with the ethical standards laid down in the Declaration of Helsinki. Written informed consent was obtained from all patients prior to inclusion in the study.

\section{Patients}

Patients requiring diagnostic bronchoscopy, including endobronchial or transbronchial biopsy via forceps or cryoprobe, were consecutively included in the study. Additional diagnostic procedures, such as bronchoalveolar lavage or brush cytology, were also permitted. Exclusion criteria were epilepsy, severe neurological or psychiatric disorder, hemodynamic instability requiring catecholamine treatment, decompensated heart failure, severe respiratory failure $\left[\mathrm{pH}<7.35\right.$, arterial oxygen pressure $\left(\mathrm{PaO}_{2}\right)<55 \mathrm{~mm} \mathrm{Hg}$ despite supplemental oxygen], history of upper airway surgery or radiation, allergy to lidocaine, propofol or midazolam, or bleeding
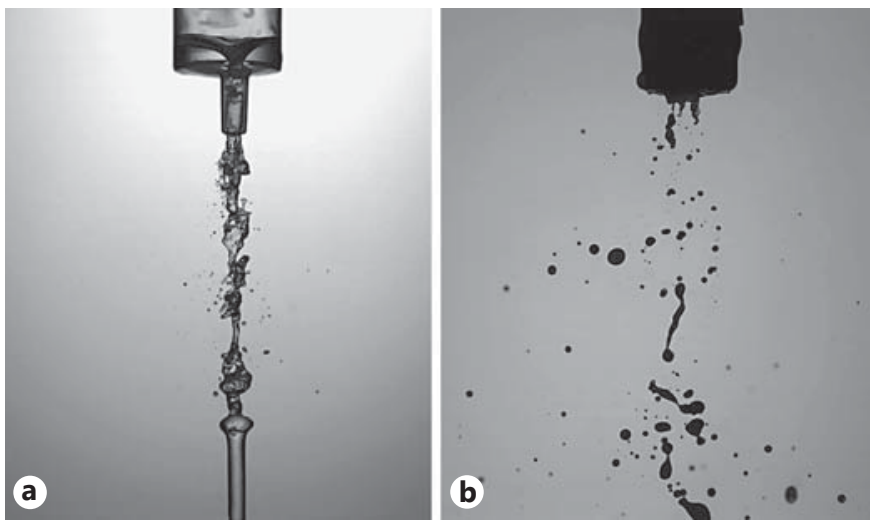

Fig. 1. High-speed images of nebulization during either syringe injection (a) or nebulizer administration (b) of lidocaine solution.

disorder. Standard laboratory tests (blood cell count, coagulation) and pulmonary function tests were performed prior to inclusion in the study.

\section{Fluid Dynamic Analysis}

Conventional photography is not suitable for analysis of the spray generated by the injection of fluid through the working channel of a bronchoscope due to the high fluid velocity. Therefore, high-speed imaging was applied to guarantee sharp images without motion blur, as previously described [7]. As shown in figure 1 , application via syringe resulted in partial nebulization while most of the fluid was injected in a straight line (fig. 1a), whereas application via nebulizer yielded a wide cone of polydisperse droplets (fig. 1b).

\section{Study Design}

For baseline measurements, arterial blood gas (ABG) analyses were done on blood taken from the arterialized earlobes of all patients while breathing room air without supplemental oxygen (ABL 800 flex; Radiometer, Copenhagen, Denmark). Oxygen saturation $\left(\mathrm{SpO}_{2}\right)$ and heart rate were continuously monitored and recorded every $5 \mathrm{~min}$ from the beginning of the intervention until an Aldrete score (a global assessment of postanesthetic condition) of at least 9 was recorded after the intervention [8]. All patients received supplemental oxygen at a flow rate of $\geq 2$ liters $/ \mathrm{min}$. The flow rate was increased before, during, and after the bronchoscopy procedure to maintain $\mathrm{SpO}_{2}$ at $\geq 95 \%$. The oxygen flow rate was recorded throughout the entire protocol. Another ABG measurement was performed after completion of the procedure. All postinterventional complications occurring within $24 \mathrm{~h}$ were recorded.

\section{Sedation and Bronchoscopy}

All procedures were performed by two experienced investigators (first and last author). Patients were randomized to lidocaine application via syringe (syringe group) or via nebulizer (nebulizer group). All patients were unaware of treatment group allocation. Nebulization of lidocaine was performed by the use of the Enk Fiberoptic Atomizer Set ${ }^{\circledR}$ (Cook Medical, Bloomington, Ind., USA) using an oxygen flow of 10 liters/min, as suggested by the manu- 
Table 1. Baseline demographic data, lung function parameters, and blood gas analysis measured during room air breathing for patients receiving lidocaine via syringe $(n=15)$ or nebulizer $(n=15)$

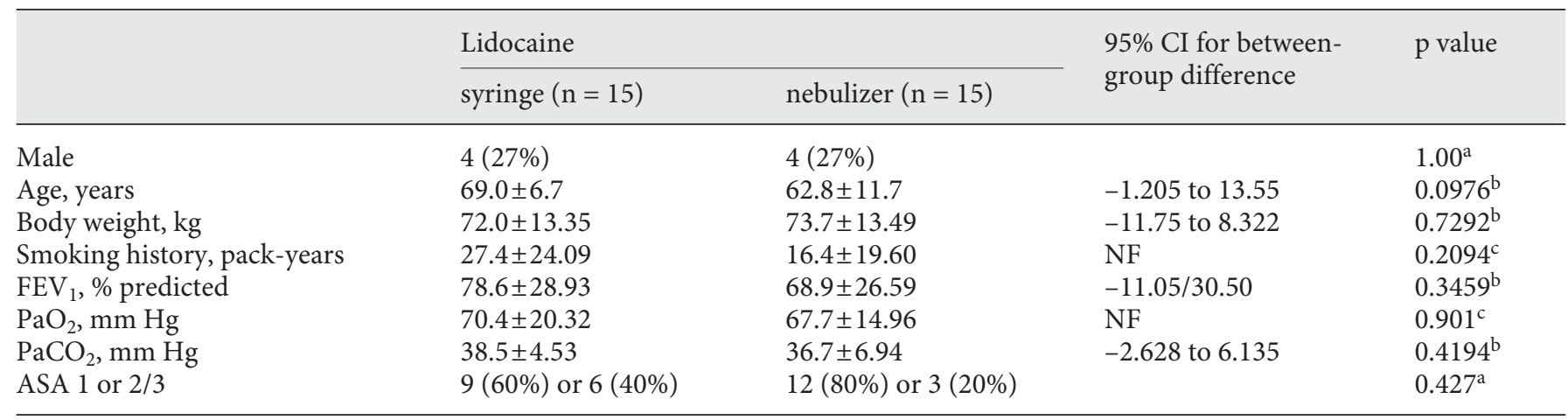

Data are presented as mean \pm standard deviation or number of patients (\%).

ASA = American Society of Anesthesiologists; $\mathrm{CI}=$ confidence interval; $\mathrm{FEV}_{1}=$ forced expiratory volume in $1 \mathrm{~s} ; \mathrm{NF}=$ normality test failed; $\mathrm{PaCO}_{2}=$ partial arterial pressure of carbon dioxide; $\mathrm{PaO}_{2}=$ arterial oxygen pressure.

${ }^{a}$ Fisher's exact test. ${ }^{b}$ Unpaired t test. ${ }^{c}$ Mann-Whitney test.

facturer. Monitoring included electrocardiogram, $\mathrm{SpO}_{2}$, pre- and postinterventional ABG analysis, and noninvasive blood pressure. Before starting bronchoscopy, patients received supplemental oxygen through a nasal cannula at a flow rate of $\geq 2$ liters $/ \mathrm{min}$, adjusted to maintain $\mathrm{SpO}_{2}$ at $\geq 95 \%$. All patients received an intravenous bolus injection of $1.5 \mathrm{mg}$ midazolam. After a 2 -min waiting period, a propofol bolus was administered, followed by a continuous propofol infusion until sufficient patient tolerance for the procedure was achieved. Flow rate and/or additional bolus doses of propofol were at the discretion of the investigator. Furthermore, if considered necessary by the investigator, bolus doses of fentanyl were also permitted.

The procedure was started when sufficient patient tolerance was obtained as judged by the investigator. Lidocaine $(20 \mathrm{mg} / \mathrm{ml})$ was administered either by nebulizer or by syringe as per randomization. All patients were intubated with a spiral armored endotracheal tube (Mallinckrodt ${ }^{\mathrm{TM}}$ Tracheal Tube Cuffed, size $8.5 \mathrm{~mm}$; Covidien, Dublin, Ireland) in order to provide a secure airway and to allow cryobiopsies to be performed if indicated. Oxygen was insufflated continuously through this tube under maintenance of spontaneous breathing during the whole procedure, as described previously $[9,10]$.

\section{Patient Tolerance (Questionnaires)}

Patient tolerance was assessed using the global tolerance score, based on a visual analogue scale ( $0=$ no bother, $100=$ intolerable), as well as four specific sensations: nausea, asphyxia, cough, and pain ( $0=$ nonexistent, $100=$ unbearable). The tolerance score, defined as the arithmetic mean of global tolerance visual analogue scale score and the mean of scores for the four specific sensations, was calculated as previously described [11]. The American Society of Anesthesiologists (ASA) score was used to assess physical status [12]. The Aldrete score was used to assess recovery after bronchoscopy [8].

\section{Statistical Analysis}

Statistical analysis was performed using GraphPadPrism (GraphPad Software, La Jolla, Calif., USA). Unless otherwise stat- ed, all data are presented as mean \pm standard deviation after testing for normal distribution (Kolmogorov-Smirnov test). Pre- and postinterventional measurements were compared using the paired $t$ test for normally distributed data. A two-group comparison was performed using the unpaired t test for normally distributed data. For normally distributed data, the $95 \%$ confidence interval (CI) of the mean is given where appropriate. For nonnormally distributed data, the Wilcoxon signed-rank test was used and the interquartile range (IQR) is given. The Fisher exact test was used for categorical data. Statistical significance was defined as a p value $<0.05$.

\section{Results}

\section{Patients}

From January 27, 2014 until January 21, 2016, a total of 30 patients (15 in each group) were included in the study. The patient characteristics at baseline are summarized in table 1 . There were no significant differences between the syringe and the nebulizer group concerning ABG, pulmonary function, smoking status, or ASA classification.

Diagnostic Interventions and Duration of the Procedure

The indications for bronchoscopy and the diagnostic interventions performed during bronchoscopy are summarized in table 2. When the number of biopsies (most patients were biopsied at different sites) was taken into account, the average number of diagnostic interventions per bronchoscopy was not different between the two groups (syringe group: $3.133 \pm 1.302$; nebulizer group: $2.933 \pm$ $1.387 ; \Delta-0.2 \mathrm{mg} / \mathrm{min}, 95 \% \mathrm{CI}-1.206$ to $0.8062 \mathrm{~mm} \mathrm{Hg}$, 


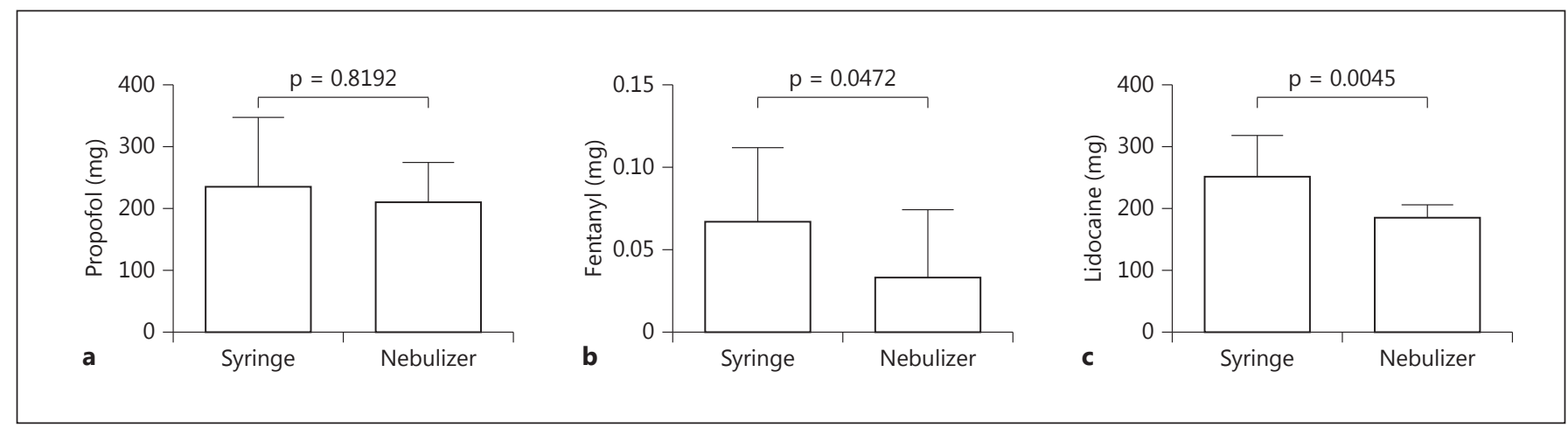

Fig. 2. Doses (mean \pm standard deviation) of intravenously administered propofol (a), intravenously administered fentanyl (b), and intrabronchially administered lidocaine $(\mathbf{c})$ in the syringe $(\mathrm{n}=15)$ and nebulizer $(\mathrm{n}=15)$ groups.

Table 2. Indications for bronchoscopy and type of diagnostic intervention during bronchoscopy in patients receiving lidocaine via syringe or nebulizer

\begin{tabular}{lrr}
\hline & Lidocaine & \\
\cline { 2 - 3 } & $\begin{array}{c}\text { syringe } \\
(\mathrm{n}=15)\end{array}$ & $\begin{array}{l}\text { nebulizer } \\
(\mathrm{n}=15)\end{array}$ \\
\hline Indications for bronchoscopy & & \\
Lung cancer & $9(60 \%)$ & $6(40 \%)$ \\
Interstitial lung disease & $3(20 \%)$ & $2(13 \%)$ \\
Unexplained pulmonary opacities & $3(20 \%)$ & $7(47 \%)$ \\
Type of diagnostic intervention & & \\
Bronchoalveolar lavage & $6(40 \%)$ & $8(53 \%)$ \\
Endobronchial biopsy & $5(33 \%)$ & $6(40 \%)$ \\
Transbronchial biopsy & $13(87 \%)$ & $10(67 \%)$ \\
Bronchial brushing & $5(33 \%)$ & $1(7 \%)$ \\
\hline Data are presented as number of patients $(\%)$. & \\
\hline
\end{tabular}

$p=0.6870)$. There was also no statistically significant difference in the mean duration of the procedure [syringe group: $35.27 \pm 21.02 \mathrm{~min}$ (IQR 25-32 min); nebulizer group: $26.93 \pm 3.92 \mathrm{~min}$ (IQR $25-30 \mathrm{~min}$ ); $\mathrm{p}=0.8669$ ].

\section{Medication}

All patients received an intravenous bolus of $1.5 \mathrm{mg}$ midazolam. No further midazolam was given. There was no significant between-group difference, neither in the total amount of administered propofol [syringe group: $236 \pm 111.9 \mathrm{mg}$ (IQR 180-260 mg); nebulizer group: $211.3 \pm 63.0 \mathrm{mg}$ (IQR 170-260 mg); $\mathrm{p}=0.8192$ ] (fig. 2a) nor in the amount of propofol based on total body weight [syringe group: $3.385 \pm 1.855 \mathrm{mg} / \mathrm{kg}$ (IQR 2.407-3.718 $\mathrm{mg} / \mathrm{kg}$ ); nebulizer group: $2.982 \pm 1.102 \mathrm{mg} / \mathrm{kg}$ (IQR $1.91-$ $3.478 \mathrm{mg} / \mathrm{kg}) ; \mathrm{p}=0.926]$. However, more patients in the syringe than in the nebulizer group received additional bolus doses of fentanyl (11 vs. 7 patients), resulting in a significantly higher dose of fentanyl in the syringe compared to the nebulizer group [syringe group: $0.067 \pm$ $0.045 \mathrm{mg}$ (IQR 0-0.1 mg); nebulizer group: $0.033 \pm 0.041$ $\mathrm{mg}$ (IQR 0-0.05 mg); $\mathrm{p}=0.0472$ ] (fig. 2b). In addition, the doses of intrabronchial lidocaine were also higher in the syringe group compared to the nebulizer group [syringe group: $250.7 \pm 67.98 \mathrm{mg}$ (IQR $240-280 \mathrm{mg}$ ); nebulizer group: $184.0 \pm 21.65 \mathrm{mg}(\mathrm{IQR} 180-200 \mathrm{mg}) ; \mathrm{p}=$ 0.0045] (fig. 2c).

\section{Vital Signs and Oxygen Flow Rate during \\ Bronchoscopy}

There was a trend towards higher mean $\mathrm{SpO}_{2}$ in the nebulizer group compared to the syringe group ( $\mathrm{p}=$ $0.0889)$. No other between-group differences in vital signs during the procedure were observed (all $\mathrm{p}>0.05$ ) (table 3). The mean oxygen flow rate tended to be higher in the syringe group compared to the nebulizer group [syringe group: $4.36 \pm 1.81$ liters/min (IQR 3-5.5 liters/min); nebulizer group: $3.53 \pm 2.15$ liters/min (IQR 2-3.6 liters/ $\min$ ); $\mathrm{p}=0.0736$ ] (fig. 3).

\section{ABG Analysis after Bronchoscopy}

Compared to preprocedural values, postprocedural partial arterial pressure of carbon dioxide $\left(\mathrm{PaCO}_{2}\right)$ levels were significantly higher in both groups (syringe group: $53.08 \pm 10.31 \mathrm{~mm} \mathrm{Hg}$ vs. $38.45 \pm 4.53 \mathrm{~mm} \mathrm{Hg}, \Delta-14.63$ $\mathrm{mm} \mathrm{Hg}, 95 \% \mathrm{CI}-19.44$ to $-9.813 \mathrm{~mm} \mathrm{Hg}, \mathrm{p}<0.0001$; 
Table 3. Vital signs during bronchoscopy in patients receiving lidocaine via syringe or nebulizer

\begin{tabular}{|c|c|c|c|c|}
\hline & \multicolumn{2}{|l|}{ Lidocaine } & \multirow{2}{*}{$\begin{array}{l}95 \% \text { CI for between- } \\
\text { group difference }\end{array}$} & \multirow[t]{2}{*}{$\mathrm{p}$ value } \\
\hline & syringe $(\mathrm{n}=15)$ & nebulizer $(\mathrm{n}=15)$ & & \\
\hline Heart rate, beats/min & $81.84 \pm 8.37$ & $84.58 \pm 15.05$ & -11.85 to 6.37 & $0.5429^{\mathrm{a}}$ \\
\hline $\mathrm{SBP}, \mathrm{mm} \mathrm{Hg}$ & $122.4 \pm 20.31$ & $118.6 \pm 10.35$ & -8.17 to 15.94 & $0.5144^{\mathrm{a}}$ \\
\hline $\mathrm{DBP}, \mathrm{mm} \mathrm{Hg}$ & $70.51 \pm 8.42$ & $70.57 \pm 4.95$ & -5.23 to 5.10 & $0.9800^{\mathrm{a}}$ \\
\hline $\mathrm{SpO}_{2}, \%$ & $92.70 \pm 3.41$ & $94.26 \pm 3.68$ & NF & $0.0889^{\mathrm{b}}$ \\
\hline
\end{tabular}

Data are presented as mean \pm standard deviation.

$\mathrm{CI}=$ Confidence interval; $\mathrm{DBP}=$ diastolic blood pressure; $\mathrm{NF}=$ normality test failed; $\mathrm{SBP}=$ systolic blood pressure; $\mathrm{SpO}_{2}=$ oxygen saturation.

${ }^{\mathrm{a}}$ Unpaired $\mathrm{t}$ test. ${ }^{\mathrm{b}}$ Mann-Whitney test.

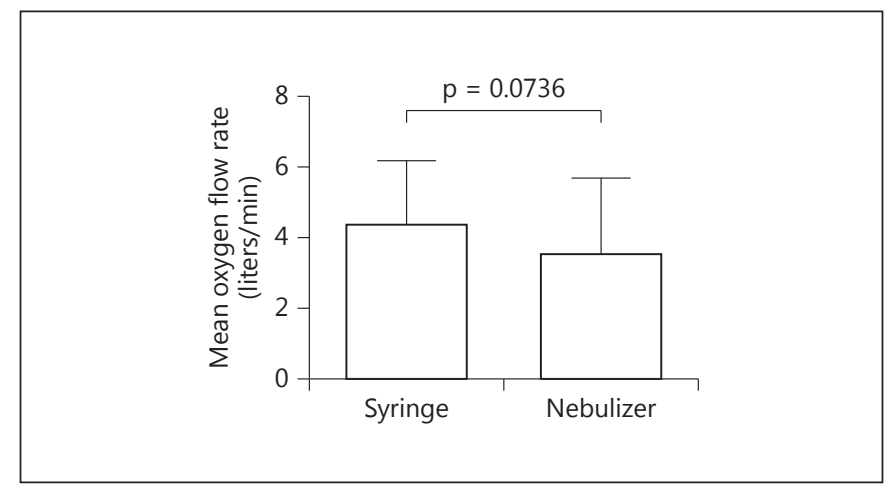

Fig. 3. Oxygen flow rate (mean \pm standard deviation) in the syringe $(\mathrm{n}=15)$ and nebulizer $(\mathrm{n}=15)$ groups.

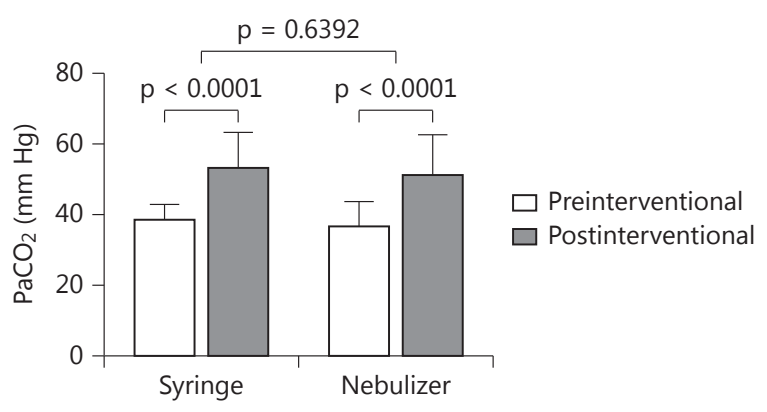

Fig. 4. Partial arterial pressure of carbon dioxide $\left(\mathrm{PaCO}_{2}\right)$ (mean \pm standard deviation) before and after bronchoscopy in the syringe $(\mathrm{n}=15)$ and nebulizer $(\mathrm{n}=15)$ groups. nebulizer group: $51.20 \pm 11.39 \mathrm{~mm} \mathrm{Hg}$ vs. $36.70 \pm 6.94$ $\mathrm{mm} \mathrm{Hg}, \Delta-14.50 \mathrm{~mm} \mathrm{Hg}$, $95 \% \mathrm{CI}-19.32$ to $-9.684 \mathrm{~mm}$ $\mathrm{Hg}, \mathrm{p}<0.0001$ ) (fig. 4). However, there were no significant differences between the two groups in $\mathrm{PaCO}_{2}$ immediately after the procedure $(\Delta 1.880 \pm 3.966 \mathrm{~mm} \mathrm{Hg}, 95 \%$ CI -6.242 to $10.00 \mathrm{~mm} \mathrm{Hg}, \mathrm{p}=0.6392$ ) or in the difference between pre- and postprocedural $\mathrm{PaCO}_{2}$ between the syringe and the nebulizer group $(\Delta-0.1267 \pm 3.174 \mathrm{~mm} \mathrm{Hg}$, $95 \% \mathrm{CI}-6.628$ to $6.374 \mathrm{~mm} \mathrm{Hg}, \mathrm{p}=0.9685$ ). In addition, postprocedural $\mathrm{PaO}_{2}$ values were similar in both groups [syringe group: $75.36 \pm 15.92 \mathrm{~mm} \mathrm{Hg}$ (IQR $67.5-78.8 \mathrm{~mm}$ $\mathrm{Hg}$ ); nebulizer group: $68.69 \pm 7.22 \mathrm{~mm} \mathrm{Hg}$ (IQR 63.3$72.6 \mathrm{~mm} \mathrm{Hg}$ ); $\mathrm{p}=0.3401]$. Furthermore, differences between pre- and postinterventional $\mathrm{PaO}_{2}$ were similar in both groups [syringe group: $4.987 \pm 6.269 \mathrm{~mm} \mathrm{Hg}$; nebulizer group: $1.040 \pm 3.855 \mathrm{~mm} \mathrm{Hg}$; $\Delta .947 \pm 7.359 \mathrm{~mm}$ $\mathrm{Hg}, 95 \% \mathrm{CI}-11.13$ to $19.02 \mathrm{~mm} \mathrm{Hg}, \mathrm{p}=0.5960]$.

\section{Complications and Recovery}

Short-term mechanical ventilation during the bronchoscopy procedure was required more often in the syringe group compared to the nebulizer group (4 vs. 2 patients). However, this difference did not reach statistical significance $(\mathrm{p}=0.6513)$. Pneumothorax occurred in 1 patient in the nebulizer group and 2 patients in the syringe group. There were eight endobronchial bleedings requiring instillation of an endobronchial vasoconstrictor (xylometazoline or adrenaline) in the syringe group compared to seven in the nebulizer group.

There was no between-group difference in the mean time span required to reach an Aldrete score of at least 9 [syringe group: $11.33 \pm 5.185 \mathrm{~min}$ (IQR 5-15 $\mathrm{min}$ ); nebulizer group: $11.0 \pm 4.12 \mathrm{~min}$ (IQR 5-15 $\mathrm{min}$ ); $\mathrm{p}=0.9656$ ] (fig. 5). 


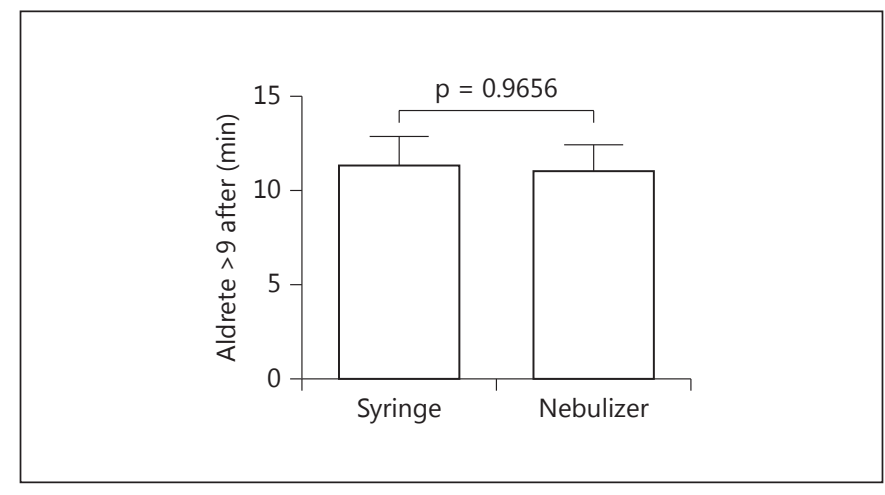

Fig. 5. Time to reach an Aldrete score $>9$ (mean \pm standard deviation) in the syringe $(n=15)$ and nebulizer $(n=15)$ groups.

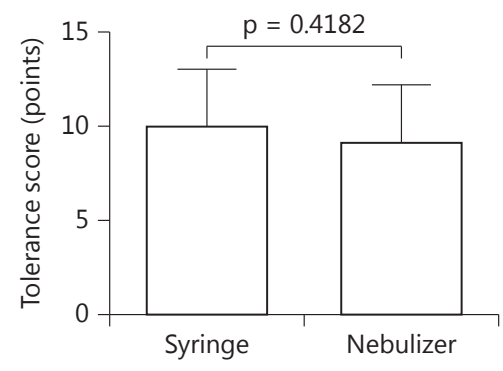

Fig. 6. Patient tolerance score (mean \pm standard deviation) in the syringe $(n=15)$ and nebulizer $(n=15)$ groups. Values for global tolerance, nausea, asphyxia, cough, and pain were assessed on a visual analogue scale $(0=$ nonexistent, $100=$ unbearable $)$. The tolerance score was defined as the arithmetic mean of global tolerance and the mean of the four specific factors.

\section{Tolerance Scores}

Global tolerance scores were similar in the two groups [syringe group: $10.00 \pm 11.76$ points (IQR 6.25-6.25 points); nebulizer group: $9.167 \pm 11.78$ points (IQR $0-6.25$ points); $\mathrm{p}=0.9656$ ] (fig. 6). Most patients (10/15 in the syringe group and $12 / 15$ in the nebulizer group) had complete amnesia for the procedure.

\section{Discussion}

The current study compared two different ways of delivering lidocaine to the airways during bronchoscopy. The results showed that intrabronchial lidocaine administration via nebulizer was associated with reduced con- sumption of fentanyl and lidocaine compared to lidocaine administration via syringe.

The use of lidocaine during bronchoscopy is recommended by different guidelines to reduce coughing during the procedure $[1,2]$. However, although topical lidocaine is widely used during bronchoscopy, there is still concern about side effects, including seizures or deterioration in pulmonary function $[13,14]$. Here, we demonstrated that lower doses of lidocaine are needed when administered via a nebulizer system. This might be due to better distribution of lidocaine on the surface of the mucosa in the tracheobronchial tree.

To the best of our knowledge, the influence of nebulizer systems on the dosage of intrabronchial lidocaine during diagnostic bronchoscopy has not been studied before. Nevertheless, a similar observation was made during fiberoptic intubation, where lidocaine $(160 \mathrm{mg})$ administered via nebulizer was associated with better cough suppression compared to lidocaine administered via syringe [15]. Therefore, the current study shows that lidocaine dosages can be reduced by the use of nebulizers, which should be of clinical importance when considering the lidocaine-related side effects described previously $[13,14]$.

Most centers perform bronchoscopy under sedation, in accordance with current guidelines [1,2]. Different sedation regimens during endoscopic procedures have been shown to increase patient comfort with a good safety profile, although most studies have been conducted in the field of gastroenterological endoscopy $[16,17]$. In the current study, a sedation level sufficient to allow fiberoptic intubation under maintenance of spontaneous breathing was needed. Therefore, midazolam induction followed by continuous propofol infusion was used. Additional fentanyl bolus doses were allowed if cough suppression was not sufficient for the procedure, as judged by the investigator. There was no difference between the two groups in the total amount of propofol administered, whereas less fentanyl was needed in the nebulizer compared to the syringe group. Opiates, including fentanyl, are widely used during bronchoscopy due to their potent antitussive properties $[3,18,19]$. However, since they are associated with known side effects, including respiratory depression, the finding of lower opiate dose requirements in the presence of nebulized lidocaine in this study are likely to be clinically relevant. The reduced need for additional fentanyl in the nebulizer group may be due to better distribution of lidocaine in the bronchial system, resulting in increased airway anesthesia and hence better cough suppression. However, this suggestion remains 
speculative because we were only able to document better lidocaine distribution in an ex vivo setting (fig. 1).

Vital signs during bronchoscopy did not differ significantly between groups in this study. Nevertheless, there was a trend towards slightly higher mean $\mathrm{SpO}_{2}$ and fewer times when $\mathrm{SpO}_{2}$ fell to $<90 \%$ in the nebulizer group, in the setting of a slightly lower mean flow rate of supplemental oxygen. This effect, though not statistically significant, could have occurred via a number of different mechanisms. On the one hand, the oxygen flow used for the nebulization of lidocaine via the nebulizer could result in better oxygenation, whereas on the other hand improved oxygenation could be due to a lower risk of respiratory depression associated with the lower dose of intravenous fentanyl used in the nebulizer group [15]. Whatever the mechanism, improved oxygenation is likely to be clinically important because deoxygenation is often observed during flexible bronchoscopy.

Overall, the results of this study show that nebulizing lidocaine during bronchoscopy appears to be a safe procedure, without any differences regarding vital signs, complications, or recovery compared to standard application of lidocaine via syringe. Furthermore, no differences in patient tolerance were observed between the nebulizer and the syringe group in the present study. However, compared to older studies, the tolerance score was very low in both groups, indicating that all patients were deeply sedated in the present study, something that was necessary due to the placement of the endotracheal tube [3]. As a result, most patients had total amnesia for the procedure. Thus, smaller differences in patient tolerance and comfort might have been missed. Nevertheless, patients tolerated an endotracheal tube with maintenance of spontaneous breathing, resulting in a secure airway for procedures with an increased risk of endobronchial bleeding [10].
Our study has several limitations that need to be noted. Firstly, only the patient (not the investigator) was unaware of treatment group allocation, which could potentially have introduced bias. However, the nature of the procedure and drug administration meant that it was not possible for investigators to be blinded to treatment allocation. Secondly, bronchoscopy was performed under deep sedation to allow fiberoptic intubation with maintenance of spontaneous breathing. As a result, the positive effects of nebulized lidocaine shown in the present study cannot be transferred to bronchoscopies being performed under light sedation or without any sedation; additional studies are needed to assess nebulized lidocaine in these settings.

In conclusion, administration of topical lidocaine via nebulizer during bronchoscopy is associated with reduced consumption of lidocaine and fentanyl compared to standard administration via syringe, and can therefore be recommended for use during diagnostic bronchoscopy.

\section{Acknowledgments}

The authors thank the patients who took part in the study and the staff of the Center for Translational \& Clinical Research Aachen (CTC-A) for their help with data collection. English language editing assistance was provided by Nicola Ryan, independent medical writer.

\section{Financial Disclosure and Conflicts of Interest}

A discount was given by Cook Medical for the purchase of the Enk Fiberoptic Atomizer Sets. Otherwise the authors have no competing interests to declare.

\section{References}

1 Du Rand IA, Blaikley J, Booton R, Chaudhuri N, Gupta V, Khalid S, Mandal S, Martin J, Mills J, Navani N, Rahman NM, Wrightson JM, Munavvar M; British Thoracic Society Bronchoscopy Guideline Group: British Thoracic Society guideline for diagnostic flexible bronchoscopy in adults: accredited by NICE. Thorax 2013;68(suppl 1):i1-i44.

2 Wahidi MM, Jain P, Jantz M, Lee P, Mackensen GB, Barbour SY, Lamb C, Silvestri GA: American College of Chest Physicians consensus statement on the use of topical anesthesia, analgesia, and sedation during flexible bronchoscopy in adult patients. Chest 2011; 140:1342-1350.
-3 Dreher M, Ekkernkamp E, Storre JH, Kabitz HJ, Windisch W: Sedation during flexible bronchoscopy in patients with pre-existing respiratory failure: midazolam versus midazolam plus alfentanil. Respiration 2010;79:307-314.

4 Antoniades N, Worsnop C: Topical lidocaine through the bronchoscope reduces cough rate during bronchoscopy. Respirology 2009; 14: 873-876.

5 MacDougall M, Mohan A, Mills J, Munavvar M: Randomized comparison of 2 different methods of intrabronchial lidocaine delivery during flexible bronchoscopy: a pilot study. J Bronchology Interv Pulmonol 2011;18:144148.
6 Malcharek MJ, Bartz M, Rogos B, Günther L, Sablotzki A, Gille J, Schneider G: Comparison of Enk Fibreoptic Atomizer with translaryngeal injection for topical anaesthesia for awake fibreoptic intubation in patients at risk of secondary cervical injury: a randomised controlled trial. Eur J Anaesthesiol 2015;32: 615-623.

-7 Thiebes AL, Reddemann MA, Palmer J, Kneer R, Jockenhoevel S, Cornelissen CG: Flexible endoscopic spray application of respiratory epithelial cells as platform technology to apply cells in tubular organs. Tissue Eng Part C Methods 2016;22:322-331. 
-8 Aldrete JA: The post-anesthesia recovery score revisited. J Clin Anesth 1995;7:89-91.

$\checkmark 9$ Babiak A, Hetzel J, Krishna G, Fritz P, Moeller P, Balli T, Hetzel M: Transbronchial cryobiopsy: a new tool for lung biopsies. Respiration 2009;78:203-208.

$>10$ Hetzel J, Eberhardt R, Herth FJF, Petermann C, Reichle G, Freitag L, Dobbertin I, Franke KJ, Stanzel F, Beyer T, Möller P, Fritz P, Ott G, Schnabel PA, Kastendieck H, Lang W, Morresi-Hauf AT, Szyrach MN, Muche R, Shah PL, Babiak A, Hetzel M: Cryobiopsy increases the diagnostic yield of endobronchial biopsy: a multicentre trial. Eur Respir J 2012; 39:685-690.

11 Putinati S, Ballerin L, Corbetta L, Trevisani L, Potena A: Patient satisfaction with conscious sedation for bronchoscopy. Chest 1999;115: 1437-1440.

-12 Mak PH, Campbell RC, Irwin MG; American Society of Anesthesiologists: The ASA Physical
Status Classification: inter-observer consistency. American Society of Anesthesiologists. Anaesth Intensive Care 2002;30:633-640.

13 Wu FL, Razzaghi A, Souney PF: Seizure after lidocaine for bronchoscopy: case report and review of the use of lidocaine in airway anesthesia. Pharmacotherapy 1993;13:72-78.

14 Peacock AJ, Benson-Mitchell R, Godfrey R: Effect of fibreoptic bronchoscopy on pulmonary function. Thorax 1990;45:38-41.

15 Piepho T, Thierbach AR, Göbler SM, Maybauer MO, Werner C: Comparison of two different techniques of fibreoptic intubation. Eur J Anaesthesiol 2009;26:328-332.

16 Akyuz U, Pata C, Senkal V, Erzin Y: Is propofol sedation with midazolam induction safe during endoscopic procedures without anesthesiologist? Hepatogastroenterology 2010; 57:685-687.

17 Rex DK, Deenadayalu VP, Eid E, Imperiale TF, Walker JA, Sandhu K, Clarke AC, Hill- man LC, Horiuchi A, Cohen LB, Heuss LT, Peter S, Beglinger C, Sinnott JA, Welton T, Rofail M, Subei I, Sleven R, Jordan P, Goff J, Gerstenberger PD, Munnings H, Tagle M, Sipe BW, Wehrmann T, Di Palma JA, Occhipinti KE, Barbi E, Riphaus A, Amann ST, Tohda G, McClellan T, Thueson C, Morse J, Meah N: Endoscopist-directed administration of propofol: a worldwide safety experience. Gastroenterology 2009;137:1229-1237; quiz 1518-1519.

18 Schlatter L, Pflimlin E, Fehrke B, Meyer A, Tamm M, Stolz D: Propofol versus propofol plus hydrocodone for flexible bronchoscopy: a randomised study. Eur Respir J 2011;38: 529-537.

19 Stolz D, Chhajed PN, Leuppi J, Pflimlin E, Tamm M: Nebulized lidocaine for flexible bronchoscopy: a randomized, double-blind, placebo-controlled trial. Chest 2005;128: 1756-1760. 